\title{
Research on the Supervision Mode of Competitive State-owned Enterprises by State-owned Capital Investment and Operation Companies
}

\author{
Yang Shui-lii ${ }^{1, a^{*}}$, Tian $\mathrm{Ye}^{1, b^{*}}$, Yang $\mathrm{Yi}^{1}$ \\ ${ }^{1}$ Xi'an University of Technology, School of Economics and Management, Xi'an, Shaanxi, China
}

\begin{abstract}
In the process of transformation of supervision of competitive state-owned enterprises, the problems that there is a blind spot in the supervision object, the lack of joint forces of the supervisory bodies, the lack of links in the supervision process, and the difficulty in appraising the supervision results have appeared in the supervision of competitive state-owned enterprises. Based on the above issues, this paper designs on the supervision of competitive state-owned enterprises, including coordinating supervision objects through governance supervision and assessment, linking supervisory entities through function coordination and achievement sharing, linking the supervision process through information supervision and platform cooperation and implementing supervision results through risk control and evidence inspection.
\end{abstract}

\section{Introduction}

In the current reform of the state-owned enterprise supervision system that focuses on "capital management", some problems hinder the effective advancement of the transition of the supervision system. As the authorized operating entity of the SASAC and the investor of state-owned enterprises (SOEs), how state-owned capital investment and operation companies can solve the regulatory problems and effectively supervise the competitive state-owned enterprises that they hold have become an important research topic.

The current research on the supervision of competitive state-owned enterprises is mainly based on the functional role of various supervision methods, and seldom combines the new situations and new problems that have emerged in the current state-owned enterprise supervision reform process; it is mainly based on the supervision of state-owned enterprises by the SASAC, and lack of State-owned capital investment and operation company's research on the supervision model of competitive state-owned enterprises. Qi Zhen et al. $(2017)^{[1]}$ pointed out that in the current environment of gradual transformation, the state-owned sector is controlled by the government on the one hand, and on the other hand is facing competition from the increasingly powerful non-state-owned sector, so it is difficult for a single regulatory system to adapt to the heterogeneity of SOEs. Regulation of commercial enterprises is more difficult and more complicated. The supervision model, assessment mechanism and policy design need to be classified and gradually implemented according to the specific situation of the enterprise ${ }^{[2]}$. For commercial

*Corresponding author:a slyangxaut@126.com

b tianye034@163.com state-owned enterprises implementing mixed-ownership reforms, whether state-controlled or state-owned enterprises, they should accept the same conditions of shareholder supervision and maintain the highest supervisory power in corporate governance ${ }^{[3]}$ and the proportion of supervisors appointed by non-state-owned shareholders is allowed to be $1 / 3$ to $1 / 2$. Competitive state-owned enterprises can encourage supervisors appointed by non-state-owned shareholders to serve as chairman of the board of supervisors ${ }^{[4]}$.

This article is based on the new situation in the reform of SOEs' supervision and reform which focuses on "managing capital", combined with the functional positioning and development goal of competitive state-owned enterprises, conduct research on the supervision model of state-owned capital investment and operation companies on competitive state-owned enterprises. The research is expected to provide a reference for the transformation of the supervision system based on "capital management".

\section{Analysis on the Supervision and Management of Competitive State-Ow -ned Enterprises}

First, there is a blind spot in the supervision object. Mainly reflected in: First of all, insufficient supervision of state-owned share-holding companies, some state-owned share-holding companies were originally subject to the current supervision of the original board of supervisors. However, after the institutional reform of the overseas board of supervisors, the original board of supervisors was revoked and its functions were merged 
into the Audit Office. It was only supervised afterwards and lead to lacking of supervision; Secondly, the imbalance between decentralization and management of state-owned enterprises, many powers have been delegated to state-owned enterprises, but the supporting management system has not been established.

Second, the regulatory bodies lack synergy. Mainly reflected in: First of all, the lack of resonance of supervisory entities, although different supervisory entities supervise state-owned enterprises based on different content and methods, the internal and external supervision of state-owned enterprises is in a decentralized pattern, so it is difficult to form a strong supervisory force; Secondly, the lack of coordination of the working mechanism, it is reflected in the lack of resource coordination among various supervisory bodies, which is prone to problems such as repeated supervision and supervision vacuum.

Third, the regulatory process lacks links. Mainly reflected in: First of all, insufficient coverage of state-owned assets, under the hierarchical authorization and supervision system of state-owned assets, it is difficult to achieve full-process and full-coverage supervision of the state-owned enterprise asset management business, and there is a lack of "penetrating" supervision models and supervision methods ${ }^{[4]}$. Secondly, the lack of supervisory information sharing, different supervisory bodies have different sources of information and lack of channels for information communication with each other.

Fourth, the results of supervision are difficult to appraise. It is difficult to identify the violating subject and determining the responsibility for the violation. Many losses in practice are not formed in a short time, there are many links, long time, and personnel turnover. It is difficult to identify the specific responsible person, so collectively take responsibility which due to the unclear rights and responsibilities of the parties.

\section{Design of Competitive State-owned Enterprise Supervision Model}

Under the background of "capital management" , competitive state-owned enterprises focus on maintaining and increasing the value of state-owned assets, with the mission requirements and functional positioning of "market profitability". Therefore, the supervision of competitive state-owned enterprises should be based on the principle of ensuring its operational autonomy and improving the internal efficiency of it. According to the problems in the supervision of competitive state-owned enterprises, design the following regulatory model:

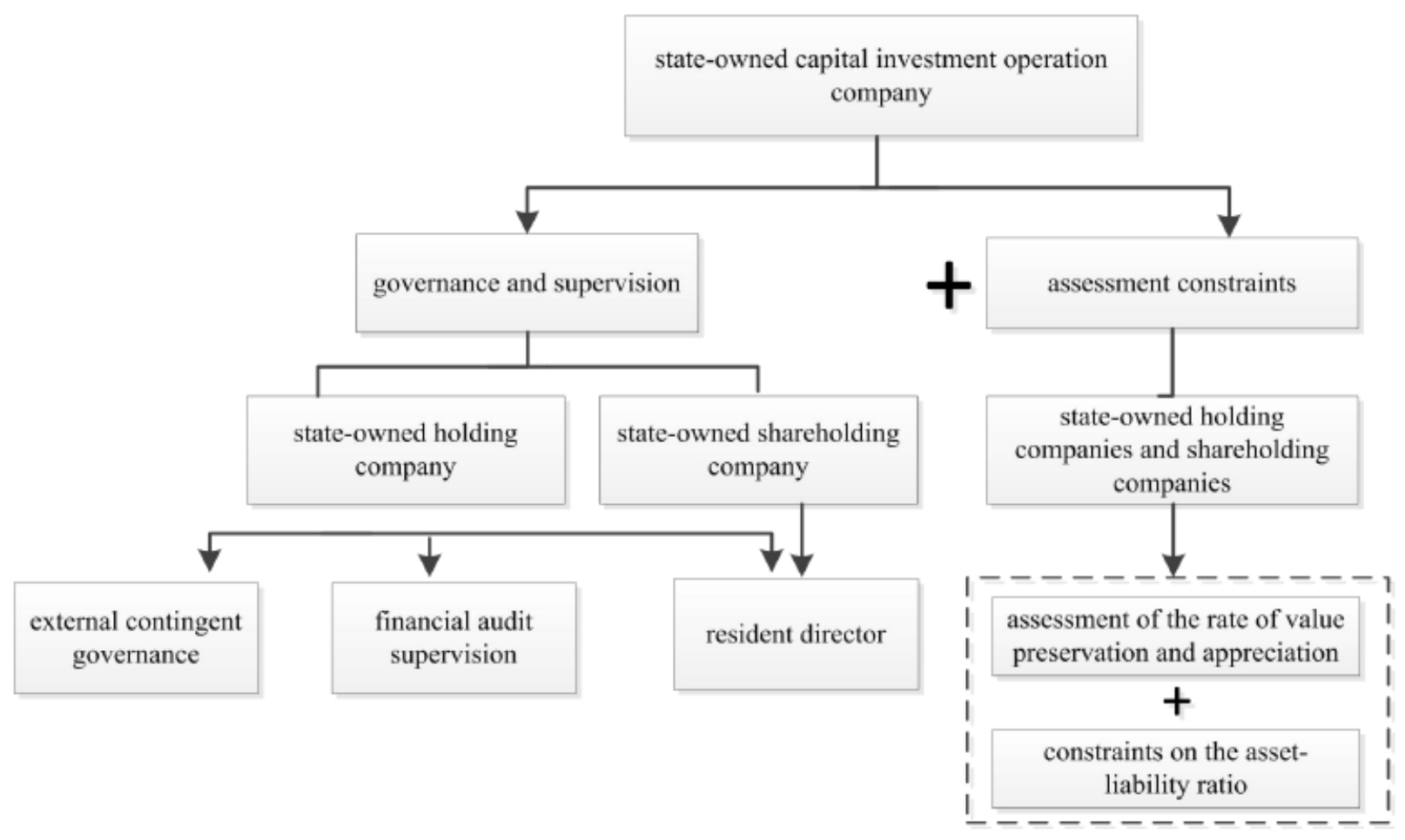

Fig.1. Coordinate Supervision Objects through Governance Supervision and Assessment.

\subsection{Coordinate Supervision Objects through Governance Supervision and Assessment}

This mode includes two aspects: On the one hand, state-owned capital investment and operation companies conduct governance supervision over SOEs based on their shareholding ratio; On the other hand, strengthen the assessment and restraint, as shown in Figure 1.

Governance and supervision include:external contingent governance, financial and audit supervision of state-owned holding companies, and supervision of the appointment of directors to state-owned holding 
companies and shareholding companies. If the company has signals such as negative business matters, major decision errors, and important financial crisis, the external contingent governance mechanism will be activated- - one is post-event audit and supervision; the other is the management change of linkage. The financial and audit supervision includes: assigning a chief financial officer, a unified approval system, and controlling major issues. Establish a financial audit and supervision system, and assign financial directors to SOEs invested in to reduce the information asymmetry. Conduct business-period audits of SOEs, the audit content includes SOEs' economic benefits, property rights changes,internal control levels, compliance with fiscal regulations and performance of leaders' economic responsibilities; formulate a unified audit system for the investment departments of SOEs; and at the same time, in order to make decisions and control the major issues ,key links and core issues in the operation of SOEs, the investment and operation company group company can limit the operation boundary, investment direction and bottom line of the state-owned enterprise. For state-owned shareholding companies after the mixed ownership reform,state-owned capital investment and operation companies select directors based on the number of shares they hold, and do not interfere with the production and operation of them. There are measures in the supervision of state-controlled and share-holding companies by sending directors:establish a full-time dispatched director system; establish a docking platform between state-owned capital investment and operation companies and dispatched directors; improve directors' performance reports and the board's annual work report system.

In the assessment and restriction of SOEs, first, the value preservation and appreciation rate assessment is carried out for the purpose of expanding and strengthening state-owned capital;secondly, the asset-liability ratio of "one enterprise, one policy" is carried out for the purpose of risk pre-control. Strengthen the asset-liability management of SOEs, strictly manage the asset mortgages, pledges, etc., regularly rate the assets.

\subsection{Link Supervisory Entities through Function Coordination and Achievement Sharing}

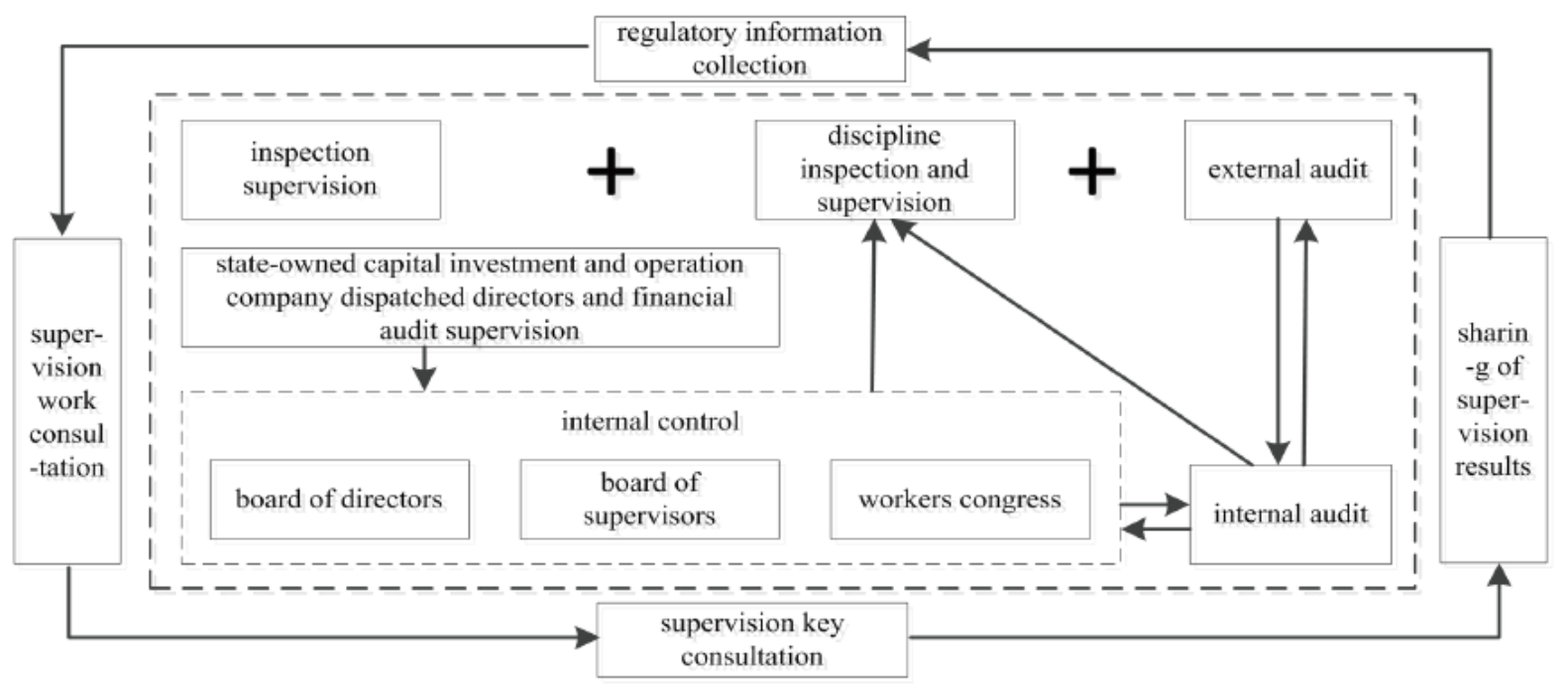

Fig.2. Link Supervisory Entities through Function Coordination and Achievement Sharing.

\subsubsection{Clearly define the functions of the supervisory body}

The internal supervision bodies of competitive state-owned enterprises include the board of directors, the board of supervisors, the employee representative assembly, and internal audit. The external supervision bodies include state-owned capital regulatory agencies, state-owned capital investment and operation companies, external audits, disciplinary inspections, and inspections.

\subsubsection{Coordinat the functions of supervisory bodies}

Combine supervisory forces with complementary functions to form coordination and complementarity of internal and external supervisory. Make the effectiveness of supervision in the decision-making and execution links, strengthen audit supervision and disciplinary inspection and supervision in the pre- and in-process supervision of SOEs, and avoid the loss of state-owned assets caused by property rights transactions, decision-making errors, and abuse of power in advance. Key aspects of operation (asset disposal, material procurement, etc.) are subject to key supervision. SOEs' internal control, internal audit, and disciplinary inspection and supervision are coordinated to share the results of supervision and strengthen the depth and effect of supervision: internal audit uses the results of internal control and monitoring to carry out special audits for outstanding problems in corporate management or as the focus of daily audits; the problems found in internal audit are the focus of internal control work, and the cause of the problems is further searched from the business process. Discipline inspection and supervision through sharing the results of internal control monitoring and 
internal audit, carry out performance monitoring or investigation and punishment of violations of regulations and disciplines, such as auditing the economic responsibility of leading cadres record the results, establish management personnel files, and provide important basis for managerial job changes and performance evaluation; internal control, internal audit and disciplinary inspection are carried out in a joint office, which is highly professional, widely involved, especially centralized funds and centralized rights. In high-risk areas, it can be the lead organization to carry out relevant supervision activities. Discipline inspection and supervision and inspection supervision implement joint supervision based on the logic of "discovering problems-tracing clues-stakeholders and other supervisory bodies-situation assessment".

\subsubsection{Coordination of supervisory entities' behavior}

Coordinating supervision behaviors through supervision information collection, supervision work consultations,supervision key consultations, and supervision results sharing, form a regulatory synergy. A supervisory committee and an information collection mechanism can be established.Each supervisory entity timely submits supervisory information to other supervisory entities, and supervisory results can be shared to form a closed-loop supervision. Establish a joint meeting system for the supervisory committee, and the supervisory committee regularly convenes joint meetings to notify the progress of supervisory work and supervise the rectification of problems

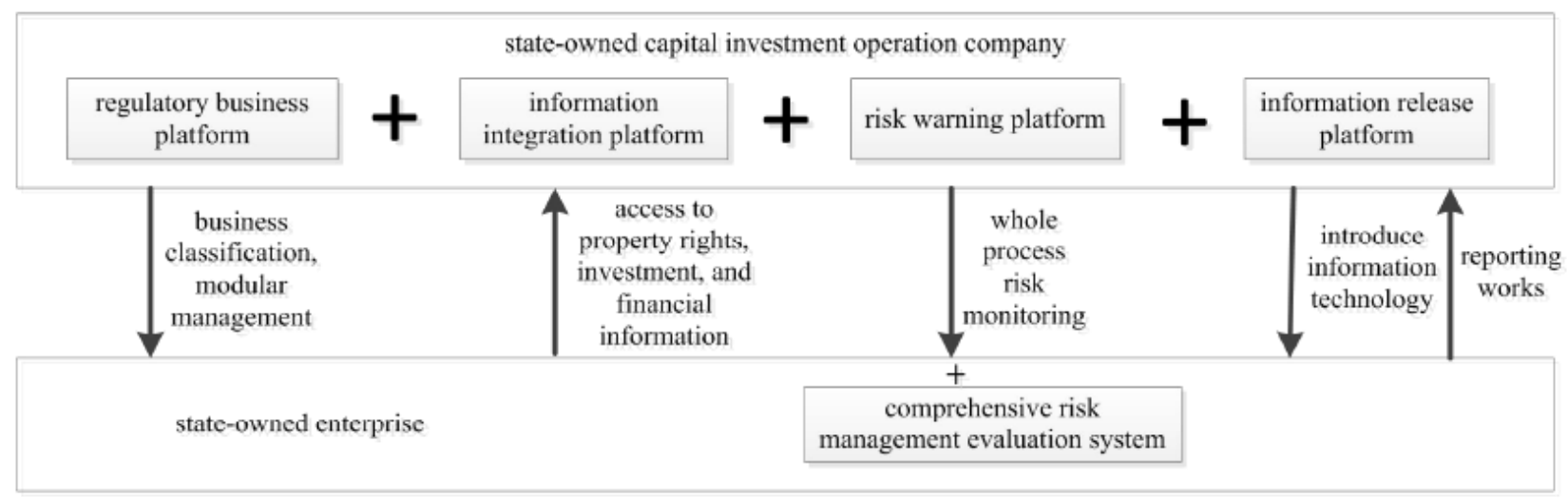

Fig.3. Link the Supervision Process through Information Supervision and Platform Cooperation.

\subsection{Link the supervision process through information supervision and platform cooperation}

This mode is embodied in the establishment of a state-owned enterprise supervision vertical and horizontal linkage information platform, the implementation of intelligent full-process dynamic supervision, and penetrating supervision of SOEs, as shown in Figure 3.

In the vertical direction, state-owned capital investment and operation companies obtain state-owned enterprise information through the information platform, and there is feedback on the information; in the horizontal direction, it includes the overall links of information integration of regulatory business management and corporate finance, risk monitoring, and information release and so on. Establish a modular and professional information collection 、 analysis and reporting mechanism, strengthen information sharing, and enhance the pertinence and timeliness of supervision. Establish an abnormal information early warning system for state-owned assets supervision, when an abnormal situation in public information is discovered, the state-owned capital investment and operation company sends abnormal information reminders to relevant departments, and cooperates with relevant departments to investigate the causes, links and effects of abnormal information. Establishing an efficient reporting method for supervisory information, information technology could be introduced into the supervisory work report of the board of directors and improve the efficiency of supervisory information reporting by the board of directors.

\subsection{Implement supervision results through risk control and evidence inspection}

This mode is based on the logic of risk prevention, risk monitoring, and risk accountability, as shown in Figure 4. 


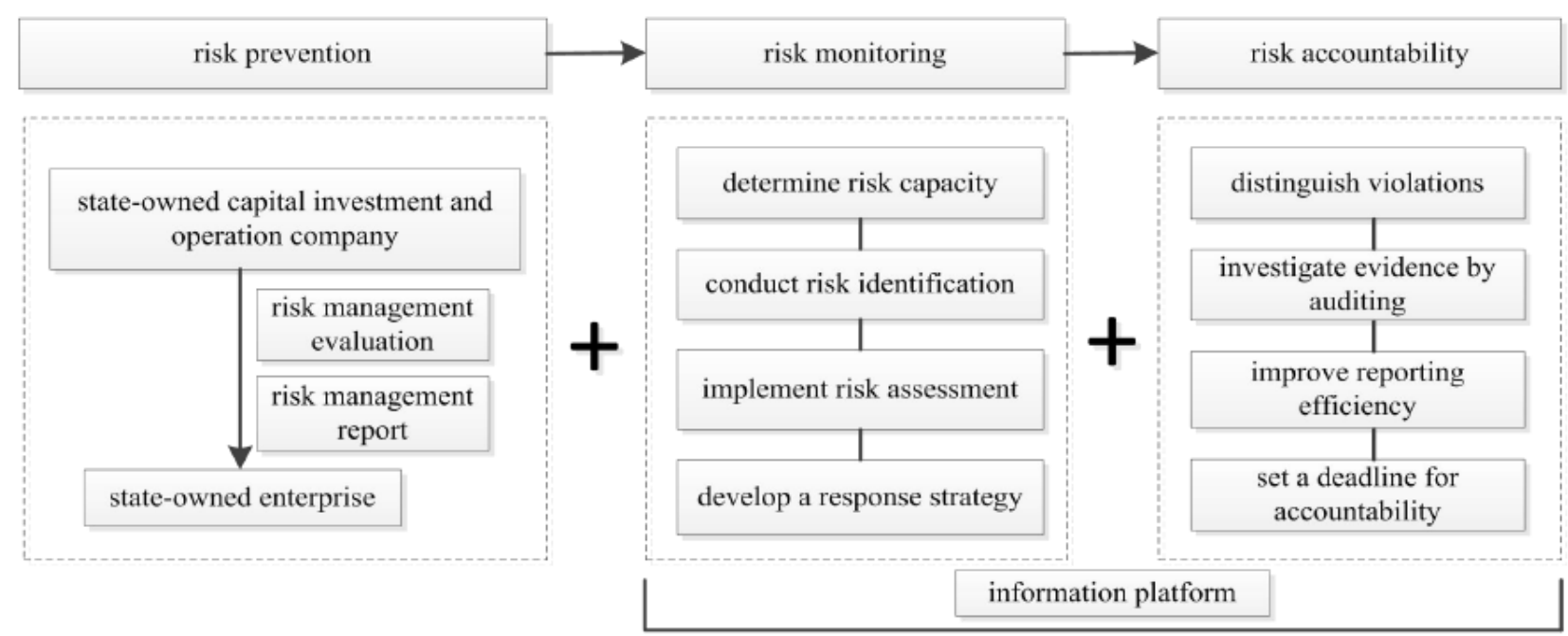

Fig.4. Implement Supervision Results through Risk Control and Evidence Inspection.

Regarding risk prevention and risk monitoring, the state-owned capital investment and operation company,as an investment enterprise, does not directly participate in the commercial operation of the state-owned enterprise, and has the right to participate in the corporate governance of the invested enterprise. In terms of risk prevention,state-owned capital investment and operation companies conduct comprehensive risk management on SOEs.Construct a comprehensive risk management system based on the strategic objectives, scale, and business system of SOEs, and urge SOEs to adopt a combination of qualitative and quantitative methods to identify, measure, evaluate, control or mitigate the business risks; and make annual reports on risk management.Establish a risk isolation system between state-owned capital investment and operation companies and the state-owned companies, and reasonably isolate business transactions between them. In terms of risk monitoring, the whole process of state-owned enterprise operation is monitored, and the enterprise's risk capacity is determined according to the internal and external environment of it.During the monitoring process, possible risks are identified and evaluated,and risk response measures are established.

Improve the methods of investigating responsibility for violations of corporate management Personnel.The four steps of distinguishing violations, investigating the evidence of violations through auditing, improving the reporting efficiency of violations, and setting the time limit for the accountability of violations should be taken to establish a responsibility investigation work system with different levels and up and down connected.In the accountability for violation of operation and investment, a distinction is made between normal operation and operation investment behavior that violates the rules to be held accountable. Use auditing methods as the evidence basis for investigating responsibility for illegal operations and investments. During the audit, focus on theloss of state-owned assets or the issue of idle state-owned assets. At the same time, optimize the reporting mechanism for illegal operation and investment behavior. In April 2020, the State-owned Assets Supervision and Administration Commission of the State Council issued the "Notice on Relevant Matters Concerning Strengthening the Reporting of Major Business Risk Events", stating that "For major business risk events discovered by enterprises or reflected by external regulatory agencies and media networks, internal control (risk) management departments should report the relevant situation in writing to the Comprehensive Supervision Bureau of the State-owned Assets Supervision and Administration Commission of the State-owned Assets Supervision and Administration Commission within 2 working days of the occurrence of the risk event; for particularly urgent major business risk events, it should be reported to the SASAC Comprehensive Supervision Bureau by telephone, etc. as soon as possible." In the accountability work, an information-based supervision platform can be used to combine pre-prevention, mid-event control, and post-event accountability to form a complete system of short-term, long-term and lifetime accountability.

\section{Conclusion}

This paper studies the regulatory model of state-owned capital investment and operation companies on competitive state-owned enterprises, and finds that the current state-owned capital investment and operation companies' supervision of competitive state-owned enterprises has some unresolved problems. The specific manifestations are the absence of regulatory objects,regulatory bodies lack synergy, the supervision process lacks links and the supervision results are difficult to appraise.Combining with the functional positioning of competitive state-owned enterprises which are focusing on maintaining and increasing value,with the principle of ensuring the operational autonomy of competitive state-owned enterprises and improving the internal efficiency of the enterprise,four regulatory models have been designed, including coordinate 
supervision objects through governance supervision and assessment,link supervisory entities through function coordination and achievement sharing,link the supervision process through information supervision and platform cooperation and implement supervision results through risk control and evidence inspection.

In the follow-up research, the relevant conclusions of this article can be verified through empirical methods; the factors in the supervision model can also be quantitatively measured, and then the influence of different supervision modes on the operating performance and supervision efficiency of competitive state-owned enterprises can be studied.

\section{Acknowledgments}

This paper is one of the stage achievements of the major project of National Social Science Fund "Research on Reform and Innovation of Supervision System of State-owned Enterprises" (17ZDA087).

\section{References}

1. Qi Zhen, Song Li Gang, He Fan. State-Owned Enterprises' Supervision in Gradual Transition Economies: Theoretical Framework and China's Practice[J]. The Journal of World Economy, 2017, 40(08): 120-142(In Chinese).

2. Liu Xian Wei. State-owned Enterprise Classified Supervision Based on Capital Management[J]. Economic Review Journal, 2017(02): 33-39(In Chinese).

3. Shen Hao, Yang Mei Ying. Research on Ownership Structure Selections and State-owned AssetsSupervision Modesunder the Mixed Ownership Reform Background--A Multi-case Perspective[J].Management Review, 2020, 32(03): 323-336(In Chinese).

4. Zhang Ming Ze, Li Zhong Hai. The Critical Path of the Evolution of SOE Reform -- Based on the Perspective of Mixed Ownership[J]. Modern Economic Research, 2016(07): 15-19(In Chinese).

5. Chi Guo Hua, Guo Rui Jia, Wang Hui Jin. Can Government Audits Improve the Institution of Internal Control? An Empirical Analysis Based on the Listed Companies of Central Enterprises Holding[J]. Nankai Business Review, 2019, 22(01): 31-41(In Chinese).

6. Hao Ying, Xie Guang Hua, Shi Rui. External Supervision, Perquisite Consumption and Enterprise Performance[J].Accounting Research, 2018(08): 42-48(In Chinese).

7. Karen, Jingrong Lin, Xiaoyan Lu, Junsheng Zhang, Ying Zheng. State-owned enterprises in China: A review of 40 years of research and practice[J]. China Journal of Accounting Research, 2020, 13: (1):31-55.

8. Zhengfei Lua, Jigao Zhu. Tracing back to the source: Understanding the corporate governance of boards of directors in Chinese SOEs[J]. China Journal of Accounting Research, 2020, 13(2): 129-145.

9. Hualin Wan, Kai Zhu, Xinyuan Chen. Career concerns, shareholder monitoring and investment efficiency: From the perspective of compensation contract rigidity in Chinese SOEs[J]. China Journal of Accounting Research, 2015, 8(1): 59-73. 